\title{
Performance and mechanism of the separation of C8 $\alpha$-olefin from F-T synthesis products using novel Ag-DES
}

\author{
$\mathrm{Hu} \mathrm{Li}{ }^{1}$, Zisheng Zhang ${ }^{2}$, Guanlun Sun ${ }^{3}$, Suli Liu ${ }^{4}$, Liangcheng An ${ }^{4}$, Xingang $\mathrm{Li}^{1}$, Hong $\mathrm{Li}^{1}$, \\ and Xin $\mathrm{Gao}^{3}$ \\ ${ }^{1}$ Tianjin University \\ ${ }^{2}$ University of Ottawa \\ ${ }^{3}$ Tianjin university \\ ${ }^{4}$ Affiliation not available
}

September 22, 2020

\begin{abstract}
As an attractive alternative technology for the separation of long chain olefin and paraffin, a novel silver-based deep eutectic solvent (Ag-DES) was prepared and utilized for 1-octene/n-octane separations. Comprehensive reactive extraction separation experiments were performed to highlight the Ag-DES concentration and operating temperature discriminations using compounds with different ratio of 1-octene/n-octane. The novel Ag-DES showed optimal separation performance regarding 1-octene/noctane and possessed the highest levels separation selectivity in the range 3.75-16.74 with excellent circulation stability in our best knowledge. Furthermore, FT-Raman measurements and quantum chemistry calculation were performed to elucidate the interaction mechanism of Ag-DES in the separation of 1-octene and n-octane, which revealed that both chemical complexation and strong physical attraction existed in the complex of Ag-DES with 1-octene rather than n-octane. This study lends important insight for the development of Ag-DES reactive extraction separation process for the energy-efficient long chain $\alpha$-olefin purification from $\mathrm{F}-\mathrm{T}$ synthesis products.
\end{abstract}

\section{Hosted file}

Manuscript-AIChE.pdf available at https://authorea.com/users/361055/articles/482585performance-and-mechanism-of-the-separation-of-c8-\%CE\%B1-olefin-from-f-t-synthesisproducts-using-novel-ag-des 